\title{
Inset fed Triple Band U-Slot Antenna for GSM900/GSM1900/WLAN Applications
}

\author{
J. Rajeshwar Goud, N. V. Koteswara Rao, A. Mallikarjuna Prasad
}

\begin{abstract}
To cover Global System for Mobile Communication(GSM) and WLAN frequency bands, three distinctive Inset fed antennas like rectangular microstrip, dualband dual slot and antennas are designed. Inset fed micostrip antenna is used for GSM1900 with an impedance bandwidth from $1.90 \mathrm{GHz}$ to $1.96 \mathrm{GHz}$. Inset fed dual band dual slot antenna is used for GSM1900 and WLAN with impedance bandwidth is considered first band from $1.90 \mathrm{GHz}$ to $1.95 \mathrm{GHz}$ and second band from $2.38 \mathrm{GHz}$ to $2.42 \mathrm{GHz}$. The proposed Inset fed triple band antenna is used for GSM900, GSM1900 and WLAN with appropriate position of slot, is to operate in frequency ranges of first band is from $920 \mathrm{MHz}$ to $940 \mathrm{MHz}$, second band is from $1.91 \mathrm{GHz}$ to $1.94 \mathrm{GHz}$ and third band is from $2.39 \mathrm{GHz}$ to $2.43 G \mathrm{Gz}$. A correlation among various feed widths, feed lengths and slot widths are exhibited in this paper.
\end{abstract}

Keywords-Inset fed, Triple band, Dual band, Slot antenna, HFSS, Patch antenna, GSM, WLAN.

\section{INTRODUCTION}

In present days, design of dual band and triple band patch antennas are highly desirable for wireless communication applications. Patch antennas inferable from their favorable circumstances, for example, low profile, reasonable to produce, light weight and simple to create. Inspite of these points of interest, there are not many inconveniences like limited bandwidth, less power dealing with limit in patch antennas [1-2]. For the most part patch antennas work in various frequency bands, separate antennas are used to cover each band which prompts space-confining issue. One approach to satisfy this necessity is utilizing various antennas, yet it will build the size and intricacy of the system. To overcome this issue, slot antennas are required which gives dual band and triple band frequencies using single antenna with appropriate slot position. From now on it diminishes the system size and multifaceted nature [3]. Large bandwidth can be achieved by adjusting the slot dimensions, which include different shapes like rectangular, triangular, circular [4], elliptical [5], triangles [6] are reported. To achieve dual band operation edge feed has been used [7]. Multi service wireless system, Wide band or dual band and triple band antennas are needed[8-11].

To obtain dual band and triple band behavior in patch antennas by providing slot and excite the antenna in orthogonal direction or Y-shape using microstrip line feeds[12-14]. Regardless, these dual band and triple band

Revised Manuscript Received on 14 August, 2019.

J. RajeshwarGoud, Ph.D Scholar, ECE Dept., JNTUK, Kakinada, A.P., India. (Email: rajeshwargoud@gmail.com)

N. V. KoteswaraRao, Professor, ECE Dept.,ChaitanyaBharathi Institute of Technology,Hyderabad, T.S., India.(Email: nvkoteswararao@gmail.com)

A. MallikarjunaPrasad,Professor, ECE Dept., University College of Engineering, JNTUK, Kakinada, A.P. India.(Email:a_malli65@yahoo.com) slot antennas are large in size, most of the wireless applications minutarized antennas are needed. In literature designed edge cut dual band slot antenna, which finds applications in Bluetooth/WLAN and WiMAX [15] and Corner cut Insetfed dual band slot antenna for PCS and Bluetooth/WLAN Applications [16] which improves the impedance matching.

A novel design of Inset fed triple band U slot, Insetfed dual band dual slot and Inset fed microstrip antennas were presented. These antennas are little in size, straightforward development and minimal effort. By providing inset feed to these antennas better impedance matching is achieved. Dual band and triple band operation is obtained with appropriate slot dimensions, which find applications in GSM and WLAN. The VSWR, return loss, peak gain, peak directivity, radiation pattern and radiation efficiency are explained as well as design details of these antennas are discussed in this paper.

\section{ANTENNA CONSTRUCTION AND DESIGN}

The Inset fed microsrip antenna geometry is showed up in fig.1, Inset fed dual band dual slot microstrip antenna configuration is showed up in fig. 2, and Inset fed tripleband U slot microstrip antenna structure is showed up in fig.3.

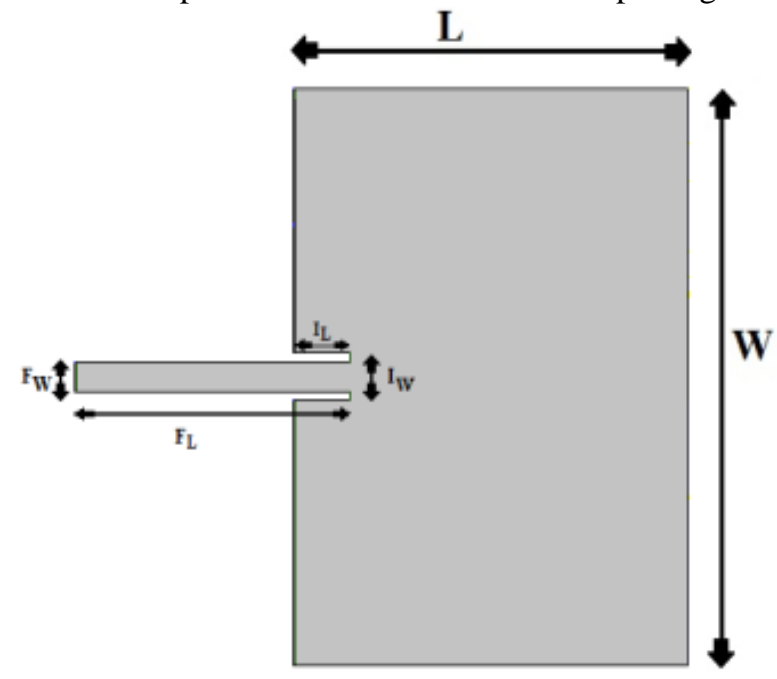

Fig. 1. Inset fed microstrip antenna

Published By: Blue Eyes Intelligence Engineering \& Sciences Publication 


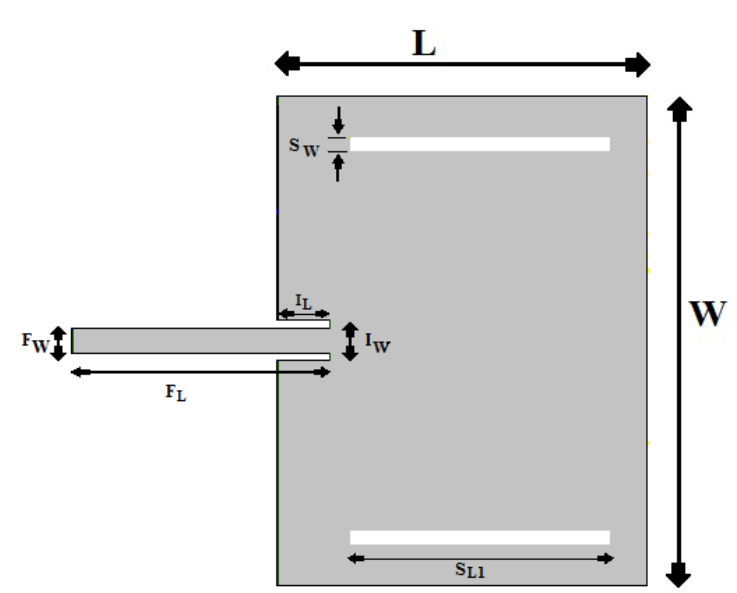

Fig. 2. Inset fed dual band dual slot antenna

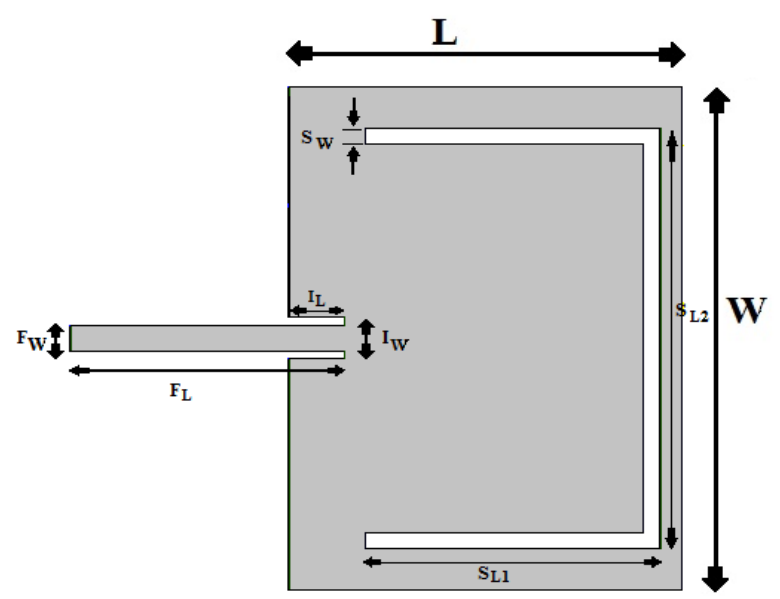

Fig. 3. Inset fed Triple band U slot antenna

These three Inset fed antennas are designed utilizing FR4 substrate with height $1.6 \mathrm{~mm}$ having $\epsilon_{\mathrm{r}}=4.4$ and $\tan \delta=0.02$. To match the impedance $50 \Omega$ strip line is used. All antenna parameters are simulated using HFSS and antenna dimensions are shown in table I.

Table1: Antenna design parameters

\begin{tabular}{|l|c|c|c|}
\hline \multicolumn{1}{|c|}{ Parameter } & $\begin{array}{c}\text { Inset fed } \\
\text { Triple } \\
\text { band U } \\
\text { slot } \\
\text { antenna } \\
(\mathbf{m m})\end{array}$ & $\begin{array}{c}\text { Inset fed } \\
\text { Dual } \\
\text { band } \\
\text { Dual } \\
\text { Slot } \\
\text { Antenna } \\
\text { (mm) }\end{array}$ & $\begin{array}{c}\text { Inset fed } \\
\text { Rectangul } \\
\text { ar } \\
\text { Antenna } \\
(\mathbf{m m})\end{array}$ \\
\hline Patch Length $(\mathrm{L})$ & 36 & 36 & 36 \\
\hline Patch Width $(\mathrm{W})$ & 48 & 48 & 48 \\
\hline Feed Length $\left(\mathrm{F}_{\mathrm{L}}\right)$ & 25 & 25 & 25 \\
\hline Feed Width $\left(\mathrm{F}_{\mathrm{W}}\right)$ & 2.8 & 2.8 & 2.8 \\
\hline $\begin{array}{l}\text { Inset feed } \\
\text { Length }\left(\mathrm{I}_{\mathrm{L}}\right)\end{array}$ & 5 & 5 & 5 \\
\hline $\begin{array}{l}\text { Inset feed Width } \\
\left(\mathrm{I}_{\mathrm{W}}\right)\end{array}$ & 4 & 4 & 4 \\
\hline Slot Length $\left(\mathrm{S}_{\mathrm{L} 1}\right)$ & 27 & 24 & - \\
\hline Slot Length $\left(\mathrm{S}_{\mathrm{L} 2}\right)$ & 40 & - & - \\
\hline Slot Width $\left(\mathrm{S}_{\mathrm{W}}\right)$ & 1.5 & 2 & - \\
\hline
\end{tabular}

\section{SIMULATION RESULTS AND DISCUSSION}

The Inset fed microstrip antenna is worked among $1.90 \mathrm{GHz}$ to $1.96 \mathrm{GHz}$ with center frequency $1.93 \mathrm{GHz}$, return loss $-20.12 \mathrm{~dB}$ is showed up in fig. 4 and VSWR 1.22 is showed up in fig. 5 , peak directivity 2.48 , radiation patterns are showed up in fig. 13, peak gain 1.17 and radiation efficiency $48 \%$. This antenna effectively used in GSM1900 band.

Inset fed dual band dual slot antenna is considered as first band among $1.90 \mathrm{GHz}$ to $1.95 \mathrm{GHz}$ with center frequency $1.92 \mathrm{GHz}$, return loss $-12.97 \mathrm{~dB}$ is showed up in fig. 6 , and VSWR 1.5 is showed up in fig. 7, and second band is from $2.38 \mathrm{GHz}$ to $2.42 \mathrm{GHz}$ with center frequency $2.4 \mathrm{GHz}$, return loss $-16.93 \mathrm{~dB}$ is showed up in fig. 6, and VSWR 1.33 is showed up in fig. 7, radiation patterns are showed up in fig.14, peak directivity 2.53, peak gain 1.24 and radiation efficiency 49\%. This antenna effectively used in GSM1900 and WLAN bands.

The proposed Inset fed triple band $U$ slot antenna is considered lower band among $920 \mathrm{MHz}$ to $940 \mathrm{MHz}$ with center frequency $930 \mathrm{MH}, \mathrm{z}$ return loss $-16.38 \mathrm{~dB}$ is showed up in fig.8, and VSWR 1.36 is showed up in fig. 9, and middle band is from $1.91 \mathrm{GHz}$ to $1.94 \mathrm{GHz}$ with center frequency $1.93 \mathrm{GHz}$, return loss $-15.84 \mathrm{~dB}$ is showed up in fig. 8, and VSWR 1.39 is showed up in fig. 9, and upper band is from $2.39 \mathrm{GHz}$ to $2.43 \mathrm{GHz}$ with center frequency $2.41 \mathrm{GHz}$, return loss $-14.88 \mathrm{~dB}$ is showed up in fig. 8, and VSWR 1.44 is showed up in fig. 9, peak directivity 2.54, radiation patterns are showed up in fig.15, peak gain 1.11 and radiation efficiency $43.79 \%$. This antenna effectively used in GSM900, GSM1900 and WLAN bands.

For Inset fed triple band antenna, good impedance matching is achieved at feed length $F_{L}=25 \mathrm{~mm}$ as compared to $F_{L}=24 \mathrm{~mm}$ and $F_{L}=26 \mathrm{~mm}$ is showed up in fig. 10. Good return loss obtained in all bands at feed width $\mathrm{F}_{\mathrm{W}}=2.8 \mathrm{~mm}$ as compared to $F_{W}=2 \mathrm{~mm}$ and $F_{W}=3 \mathrm{~mm}$ is showed up in fig. 11 . Desired bandwidth is obtained in three bands at slot width $\mathrm{S}_{\mathrm{W}}=1.5 \mathrm{~mm}$ as compared to $\mathrm{S}_{\mathrm{W}}=1 \mathrm{~mm}$ and $\mathrm{S}_{\mathrm{W}}=2 \mathrm{~mm}$ is showed up in fig. 12 .

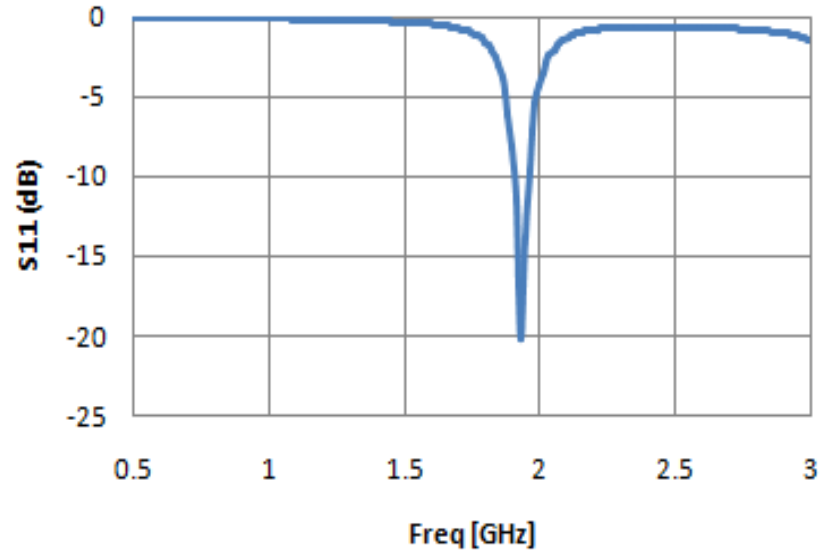

Fig. 4: Return loss (S11) of an Inset fed microstrip antenna 


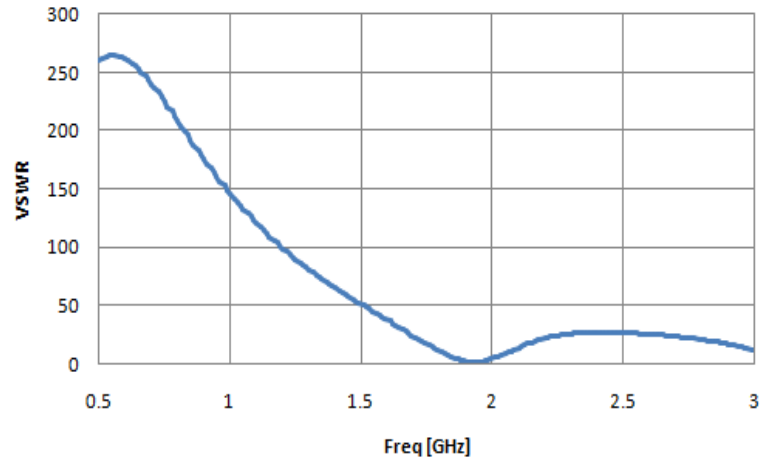

Fig. 5: VSWR of an Inset fed microstrip antenna

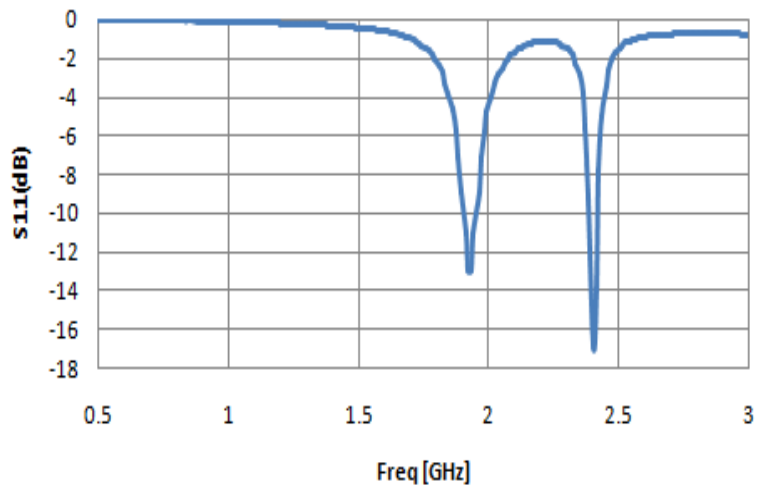

Fig. 6: Return loss (S11) of an Inset fed dual band dual slot antenna

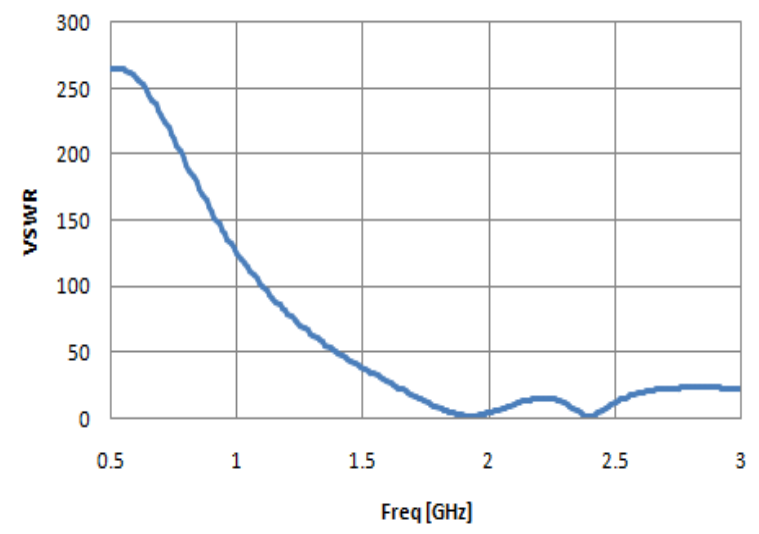

Fig. 7: VSWR of an Inset fed dual band dual slot antenna

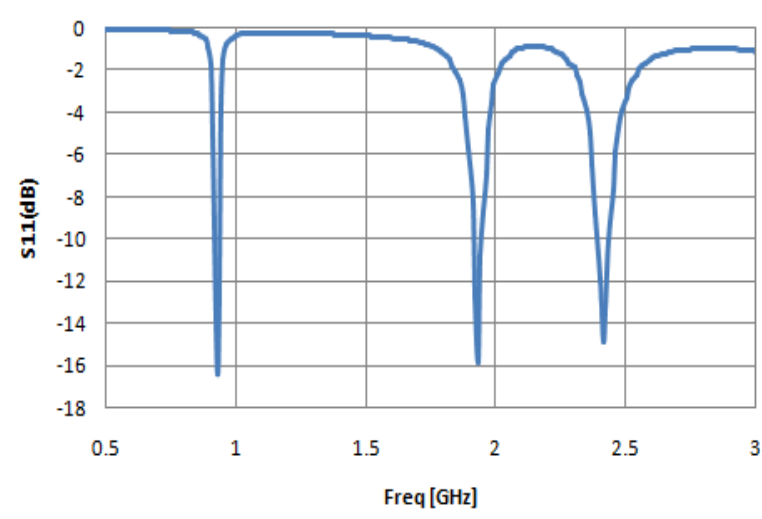

Fig. 8: Return loss (S11) of an Inset fed triple band U slot antenna

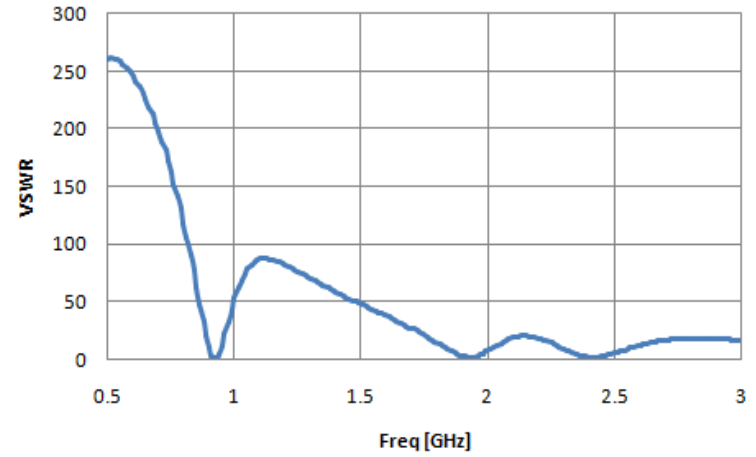

Fig. 9: VSWR of an Inset fed triple band U slot antenna

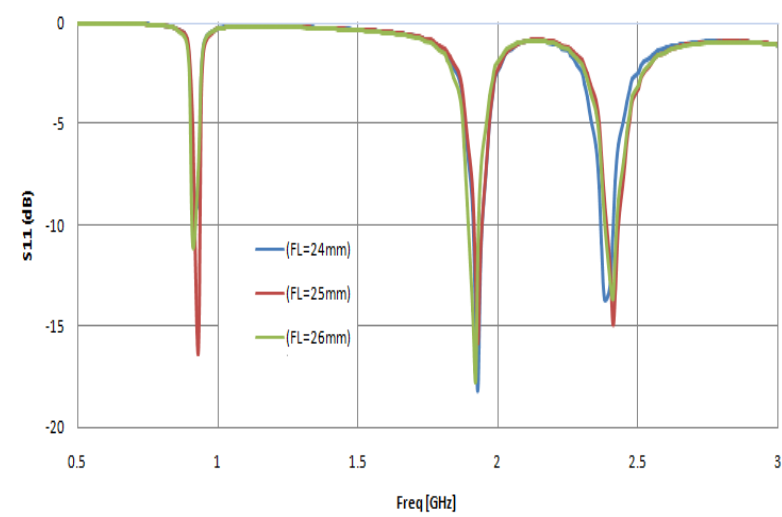

Fig. 10: Return loss (S11) comparison of different feed lengths of an Inset fed triple band $U$ slot antenna

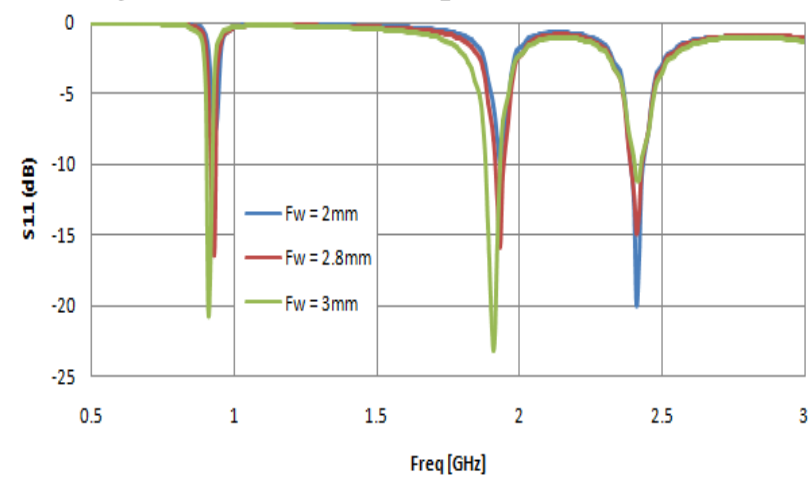

Fig. 11: Return loss (S11) comparison of different feed widths of an Inset fed triple band $U$ slot antenna

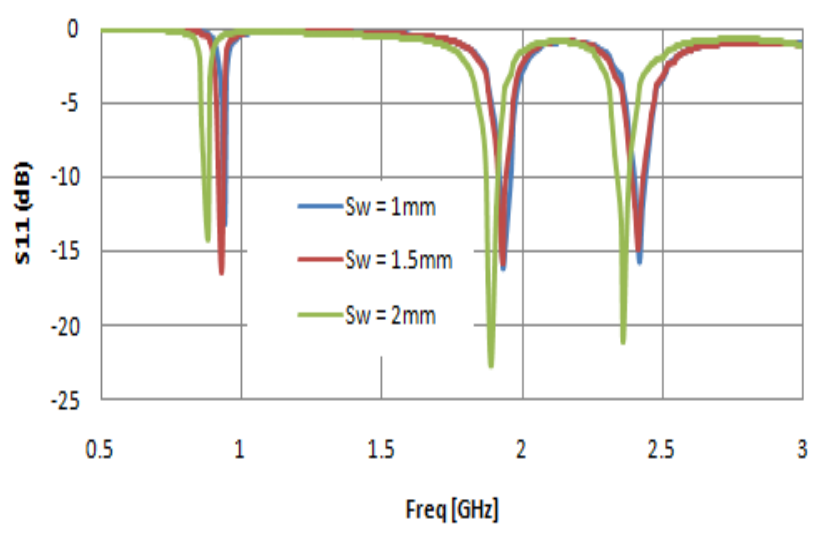

Fig. 12: Return loss (S11) comparison of different slot widths of an Inset fed triple band $U$ slot antenna

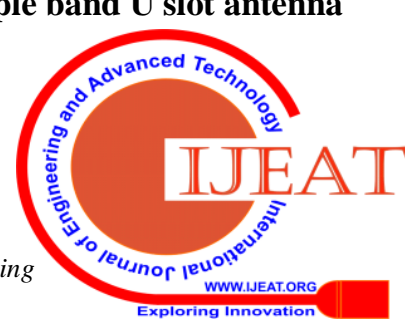




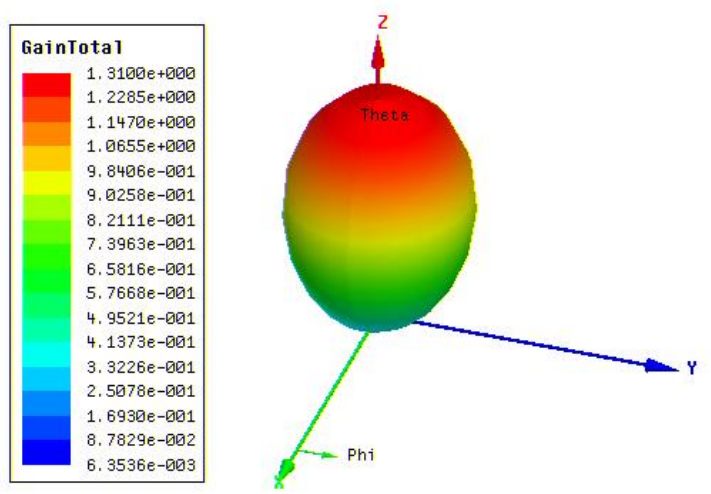

Fig. 13: Radiation pattern (GAIN) of a rectangular microstrip antenna

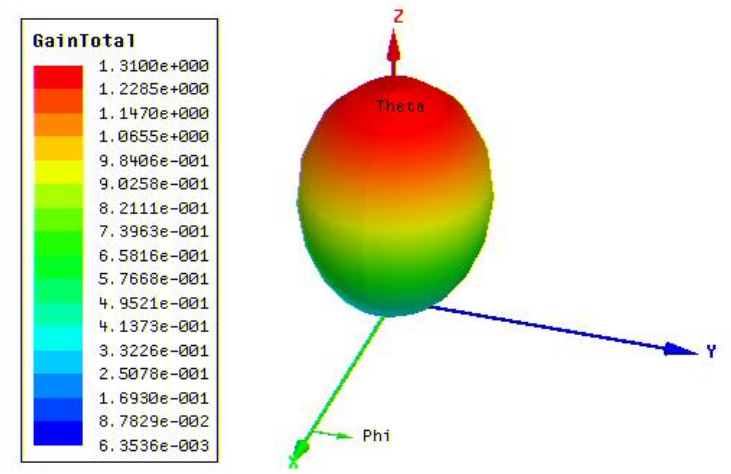

Fig.14: Radiation pattern (GAIN) of an Inset fed dual band dual slot antenna
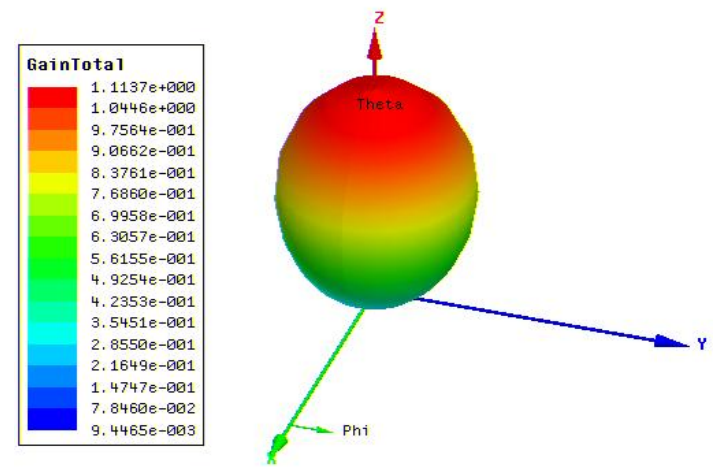

Fig. 15: Radiation pattern (GAIN) of an Inset fed triple band $U$ slot antenna

\section{CONCLUSION}

Antennas are simulated at specified frequencies and antenna parameters are explained. The Inset fed triple band antenna is to operate in three specified bands in which the lower band with center frequency $930 \mathrm{MHz}$ which meet the requirement of GSM900, middle band with center frequency $1.93 \mathrm{GHz}$ which meet the requirement of GSM1900 and upper band with center frequency $2.41 \mathrm{GHz}$ which meet the requirement of WLAN, The Inset fed dualband dual slot antenna is to operate in two specified bands in which first band with center frequency $1.92 \mathrm{GHz}$ which meet the requirement of GSM1900 and second band with center frequency $2.4 \mathrm{GHz}$, which meet the requirement of WLAN. The Insetfed microstrip antenna is to operate at center frequency $1.93 \mathrm{GHz}$, which finds the application of
GSM1900. Every one of the three antennas has over $43 \%$ efficiency with least peak directivity 2.48 .

\section{REFERENCES}

1. Surendra K. Gupta, Ashish Sharma, Binod K. Kanaujia, ShekarRudra, Ritu Raj Mishra and G.P. pandey, "Orthogonal slit cut stacked circular patch Microstrip antenna for Multiband operation". Microwave Optical Technology letters/ Volume 55, No. 4, April 2013.

2. S.-W. Qu, J.-L. Li, J.-X. Chen, and Q. Xue, "Ultrawideband strip- loaded circular slot antenna with improved radiation patterns," IEEE Trans. Antennas Propag., vol. 55, no. 11, pp. 3348-3353, Nov. 2007.

3. P. Li, J. Liang, and X. Chen, "Study of printed elliptical/circular slot antennas for ultrawideband applications," IEEE Trans. Antennas Propag., vol. 54, no. 6, pp. 1670-1675, Jun. 2006.

4. S.-W. Qu, J.-L. Li, J.-X. Chen, and Q. Xue, "Ultrawideband strip- loaded circular slot antenna with improved radiation patterns," IEEE Trans. Antennas Propag., vol. 55, no. 11, pp. 3348-3353, Nov. 2007.

5. P. Li, J. Liang, and X. Chen, "Study of printed elliptical/circular slot antennas for ultrawideband applications," IEEE Trans. Antennas Propag., vol. 54, no. 6, pp. 1670-1675, Jun. 2006.

6. W.-S. Chen and F.-M. Hsieh, "Broadband design of the printed trian- gular slot antenna," in Proc. IEEE APS Int. Symp., Jul. 2004, vol. 4, pp. 3733-3736.

7. Y. F. Liu, K. L. Lau, Q. Xue, and C. H. Chan, "Experimental studies of printed wide-slot antenna for wide-band applications," IEEE Antennas Wireless Propag. Lett., vol. 3, pp. 273-275, 2004.

8. D.N.Elsheakh, H.A.Elsadek, E.A.Abdallah, M.F.Iskander, and H. Elhenawi, "Reconfigurable single and multiband inset feed microstrip patch antenna for wireless communication devices," Progress in Electromagnetics Research C,vol.12,pp.191-201, 2010.

9. S. Verma, J. A. Ansari, and M. K. Verma, "A novel compact multi-band microstrip antenna with multiple narrow slits," Microwave and Optical Technology Letters, vol.55,no.6,pp. 1196-1198, 2013.

10. L. Xu, Z. Y. Xin, and J. He, "A compact triple-band for $k$ shaped antenna for WLAN/WiMAX applications," Progress in Electromagnetics Research Letters,vol.40,pp.61-69,2013.

11. L. Dang, Z.-Y. Lei, Y.-J. Xie, G.-L. Ning, and J. Fan, "A compact microstrip slot triple-band antenna for WLAN/WiMAX applications," IEEE Antennas Wireless Propag. Lett., vol. 9, pp. 1178-1181, 2010.

12. D.D. Krishna, M. Gopikrishna, C.K. Anandan, P. Mohanan, and K.Vasudevan, Compact dual band slot loaded circular microstrip antenna with a superstrate, ProgrElectromagn Res 83 (2008), 245-255.

13. J. P. Thakur, J.-S. Park, B.-J. Jang, and H.-G. Cho, "Smallsize quad band microstrip antenna," Microwave and Optical Technology Letters ,vol.49,no.5,pp.997$1001,2007$.

14. J. Pei, A.-G. Wang, S. Gao, and W. Leng, "Miniaturized triple-band antenna with a defected ground plane for WLAN/WiMAX applications," IEEE Antennas and Wireless Propagation Letters, vol. 10, pp. 298-301, 2011.

15. J. RajeshwarGoud, N.V. KoteswaraRao, and A. Mallikarjuna Prasad, "Edge cut Dual-band slot antenna for Bluetooth/WLAN and WiMAX applications," Soft

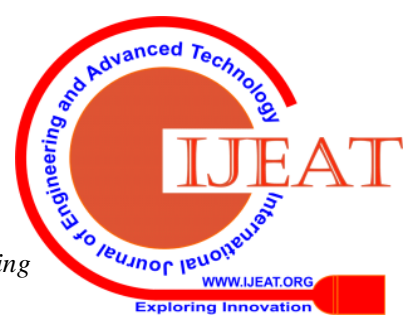


Computing and Signal Processing, Advances in Intelligent Systems and Computing 900, Springer., Vol 1, pp. 561-569, Jan. 2019.

16. J. Rajeshwargoud, N. V. KoteswaraRao and A. Mallikarjuna Prasad, "Corner cut Inset-fed Dual-Band Slot Antenna for PCS and Bluetooth/WLAN Applications," 2018 IEEE Indian Conference on Antennas and Propogation (InCAP), Hyderabad, India, 2018, PP. 1-4.

\section{AUTHORS PROFILE}

1. J. RajeshwarGoud is a Ph.D scholar, JNTUK, Kakinada. He worked as an Assistant Professor for 11years in the Department of Electronics and Communication Engineering, St. Martin's Engineering College, Hyderabad, Telangana, India. He awarded UGC-NET Lectureship in 2013. He is currently working toward the Ph.D degree in the Department of Electronics and Communication Engineering, JNTUK, Kakinada, Andhra Pradesh, India. His current research interest is in multiband antennas.

2. Dr N. V. KoteswaraRao is Professor and HOD, Department of ECE, CBIT, Hyderabad. He is also Chairman, Board studies of ECE under Autonomous and also Coordinator for TEQIP-II. He is best teacher awardees' and best paper awardees' in an international conference. Presently he is working on a project from DRDO and one in-house project on reconfigurable Microstrip antennas. He is guiding Ph.D. Research Scholars. He is associated with Center for Excellence in Microwave Engineering of Osmania University, Hyderabad.

3. Dr A. Mallikarjuna Prasad is Professor and VICE PRINCIPAL, UCEK, JNTUK, Kakinada. He obtained his Ph.D from Andhra University. He worked as HOD, Department of ECE, UCEK, JNTUK. He worked as Controller of Examinations in JNTUK. His research interests include Wireless Communications, Biomedical Instrumentation and Microwave antennas. 